\title{
Seismic Induced Global Collapse of Non-deteriorating Frame Structures
}

\author{
Christoph Adam and Clemens Jäger
}

\begin{abstract}
In a severe seismic event the destabilizing effect of gravity loads, i.e. the P-delta effect, may be the primary trigger for global collapse of quite flexible structures exhibiting large inelastic deformations. This article deals with seismic induced global collapse of multi-story frame structures with non-deteriorating material properties, which are vulnerable to the P-delta effect. In particular, the excitation intensity for P-delta induced structural collapse, which is referred to as collapse capacity, is evaluated. The initial assessment of the structural vulnerability to P-delta effects is based on pushover analyses. More detailed information about the collapse capacity renders Incremental Dynamic Analyses involving a set of recorded ground motions. In a simplified approach equivalent single-degree-of-freedom systems and collapse capacity spectra are utilized to predict the seismic collapse capacity of regular multi-story frame structures.
\end{abstract}

Keywords Collapse capacity spectra $\cdot$ Dynamic instability $\cdot$ P-delta

\section{Introduction}

In flexible structures gravity loads acting through lateral displacements amplify structural deformations and stress resultants. This impact of gravity loads on the structural response is usually referred to as P-delta effect. For a realistic building in its elastic range the P-delta effect is usually negligible. However, it may become of significance at large inelastic deformations when gravity loads lead to a negative slope in the post-yield range of the lateral load-displacement relationship. In such

\footnotetext{
C. Adam ( $\varangle)$

University of Innsbruck, Department of Civil Engineering Sciences, 6020 Innsbruck, Austria e-mail: christoph.adam@uibk.ac.at

C. Jäger

University of Innsbruck, Department of Civil Engineering Sciences, 6020 Innsbruck, Austria e-mail: clemens.jaeger@uibk.ac.at
} 
Fig. 1 Normalized bilinear cyclic behavior of a SDOF system with and without P-delta effect

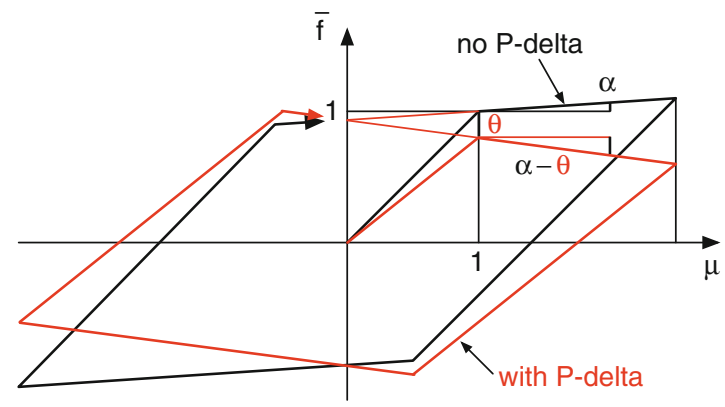

a situation large gravity loads combined with seismically induced large inelastic deformations amplify the lateral displacements in a single direction. The seismic collapse capacity of the structure is exhausted at a rapid rate, and the system is no longer able to sustain its own gravity loads. Additionally, material deterioration accelerates P-delta induced seismic collapse.

A profound insight into the P-delta effect on the inelastic seismic response of structures is given e.g. by Bernal [1], Gupta and Krawinkler [2], Aydinoglu [3], Ibarra and Krawinkler [4], and Lignos and Krawinkler [5]. Asimakopoulos et al. [6] and Villaverde [7] provide an overview on studies dealing with collapse by dynamic instability in earthquake excited structures.

In an inelastic single-degree-of-freedom (SDOF) system the gravity load generates a shearing of its hysteretic force-displacement relationship. Characteristic displacements (such as the yield displacement) of this relationship remain unchanged, whereas the characteristic forces (such as the strength) are reduced. As a result, the slope of the curve is decreased in its elastic and post-elastic branch of deformation. The magnitude of this reduction can be expressed by means of the so-called stability coefficient [8]. As a showcase in Fig. 1 the P-delta effect on the hysteretic behavior of a SDOF system with non-deteriorating bilinear characteristics is visualized. In this example the post-yield stiffness is negative because the stability coefficient $\theta$ is larger than the hardening ratio $\alpha$.

Fundamental studies of the effect of gravity on inelastic SDOF systems subjected to earthquakes have been presented in Bernal [8] and MacRae [9]. Kanvinde [10], and Vian and Bruneau [11] have conducted experimental studies on P-delta induced collapse of SDOF frame structures. Asimakopoulos et al. [6] propose a simple formula for a yield displacement amplification factor as a function of ductility and the stability coefficient. Miranda and Akkar [12] present an empirical equation to estimate the minimum lateral strength up to which P-delta induced collapse of SDOF systems is prevented. In Adam et al. [13-15] so-called collapse capacity spectra have been introduced for the assessment of the seismic collapse capacity of SDOF structures.

In multi-story frame structures gravity loads may impair substantially the complete structure or only a subset of stories [2]. The local P-delta effect may induce collapse of a local structural element, which does not necessarily affect the stability of the complete structure. An indicator of the severity of the local P-delta effect is 
the story stability coefficient, Gupta and Krawinkler [2]. Alternatively, Aydinoglu [3] proposes the use of the geometric story stiffness instead of the story stability coefficient. However, a consistent relationship between the local P-delta effect and the global P-delta effect, which characterizes the overall impact of gravity loads on the structure, cannot be established due to dynamic interaction between adjacent stories in a multi-story frame structure [2].

In several papers, see e.g. Takizawa and Jennings [16], Bernal [17], Adam et al. [18], it is proposed to assess the global P-delta effect in frame structures by means of equivalent single-degree-of-freedom (ESDOF) systems. If the story drifts remain rather uniformly distributed over the height, regardless of the extent of inelastic deformation, a global assessment of the P-delta effect by means of ESDOF systems is not difficult. Thereby, it is assumed that P-delta is primarily governed by the fundamental mode. As recently shown [19] this assumption holds true also for tall buildings. However, if a partial mechanism develops, the global P-delta effect will be greatly affected by the change of the deflected shape, and it will be amplified in those stories in which the drift becomes large [1,3]. In such a situation an adequate incorporation of P-delta effects in ESDOF systems is a challenging task.

In this paper a methodology is presented, which allows a fast quantification of the global P-delta effect in highly inelastic regular MDOF frame structures subjected to seismic excitation. Emphasis is given to the structural collapse capacity. Results and conclusions of this study are valid only for non-deteriorating cyclic behavior, i.e. strength and stiffness degradation is not considered.

\section{Structural Vulnerability to Global P-Delta Effects}

\subsection{Assessment of the Vulnerability to Global P-Delta Effects}

Initially, it must be assessed whether the considered structure is vulnerable to P-delta effects. Strong evidence delivers the results of a global pushover analysis [2]. During this nonlinear static analysis gravity loads are applied, and subsequently the structure is subjected to lateral forces. The magnitude of these forces with a predefined invariant load pattern is amplified incrementally in a displacement-controlled procedure. As a result the global pushover curve of the structure is obtained, where the base shear is plotted against a characteristic deformation parameter. In general the lateral displacement of the roof is selected as characteristic parameter. It is assumed that the shape of the global pushover curve reflects the global or the local mechanism involved when the structure approaches dynamic instability.

In Fig. 2 the effect of gravity loads on the global pushover curve of a multi-story frame structure is illustrated. Figure 2a shows the global pushover curve, where gravity loads are either disregarded or of marginal importance. The pushover curve of Fig. 2b corresponds to a very flexible multi-story frame structure with a strong impact of the P-delta effect leading to a reduction of the global lateral stiffness. In 
a

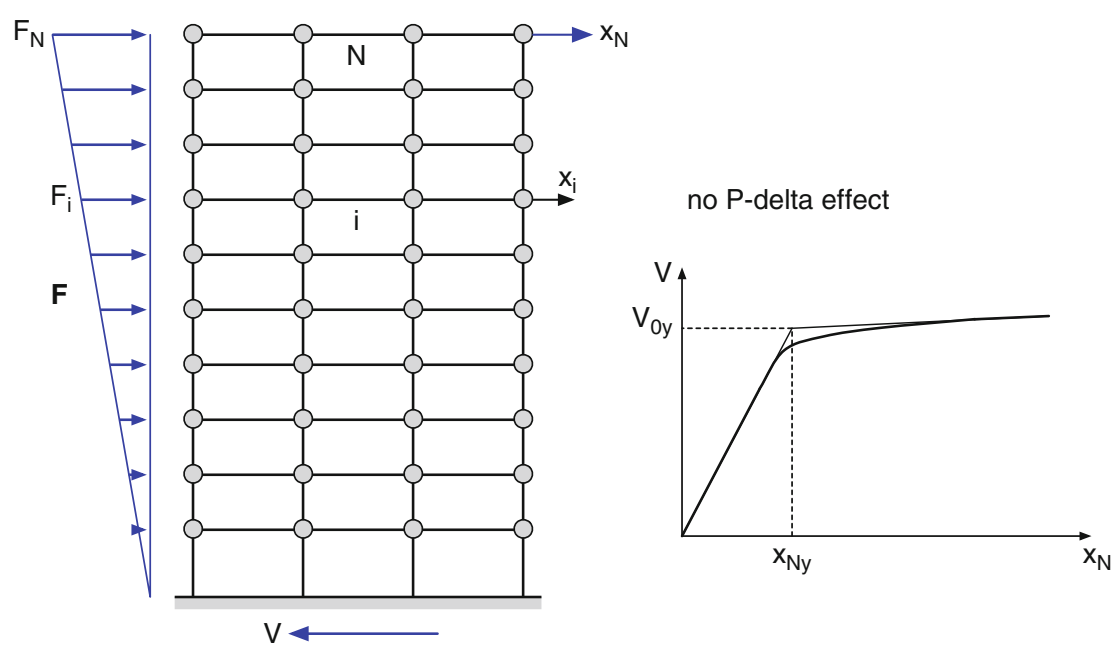

b

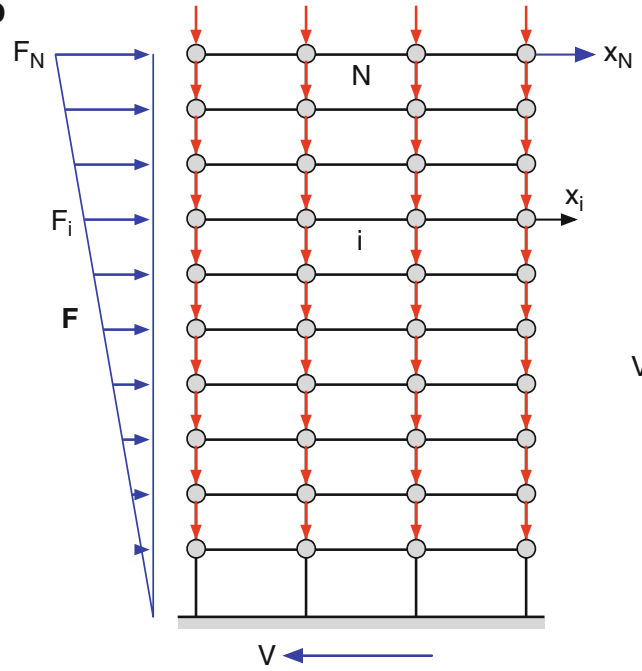

P-delta effect included

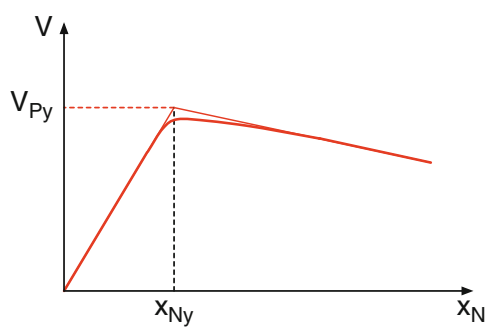

Fig. 2 Multi-story frame structure and corresponding global pushover curves. (a) Pushover analysis disregarding the P-delta effect. (b) Pushover analysis considering the P-delta effect

very flexible structures gravity loads even may generate a negative post-yield tangent stiffness as shown in Fig. 2b [20]. If severe seismic excitation drives such a structure in its inelastic branch of deformation a state of dynamic instability may be approached, and the global collapse capacity is attained at a rapid rate. From these considerations follows that a gravity load induced negative post-yield tangent stiffness in the global pushover curve requires an advanced investigation of P-delta effects [2]. It is emphasized that collapse induced by static instability must be investigated separately. 


\subsection{Example}

Exemplarily, the structural vulnerability to P-delta effects of a generic single-bay 15-story frame structure according to Fig. 3a is assessed. All stories are of uniform height $h$, and they are composed of rigid beams, elastic flexible columns, and rotational springs at the ends of the beams. Nonlinear behavior at the component level is modeled by non-degrading bilinear hysteretic behavior of the rotational springs (compare with Fig. 3b) to represent the global cyclic response under seismic excitation. The strength of the springs is tuned such that yielding is initiated simultaneously at all spring locations in a static pushover analysis (without gravity loads) under an inverted triangular design load pattern. To each joint of the frame an identical point mass is assigned. The bending stiffness of the columns and the stiffness of the springs are tuned to render a straight line fundamental mode shape. Identical gravity loads are assigned to each story to simulate P-delta effects. This implies that axial column forces due to gravity increase linearly from the top to the bottom of the frame. The frame structure has a fundamental period of vibration of $T_{1}=3.0 \mathrm{~s}$, which makes it rather flexible. The base shear coefficient, defined as

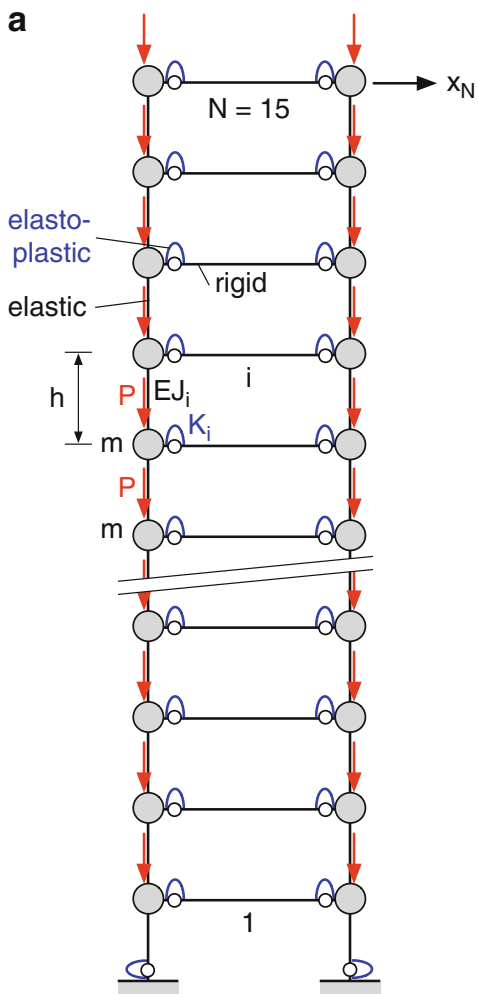

b

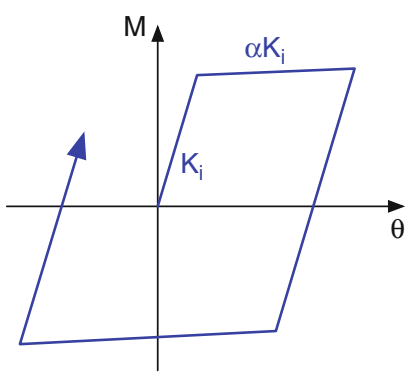

Fig. 3 (a) Generic 15-story frame structure. (b) Bilinear hysteretic loop of the rotational springs 


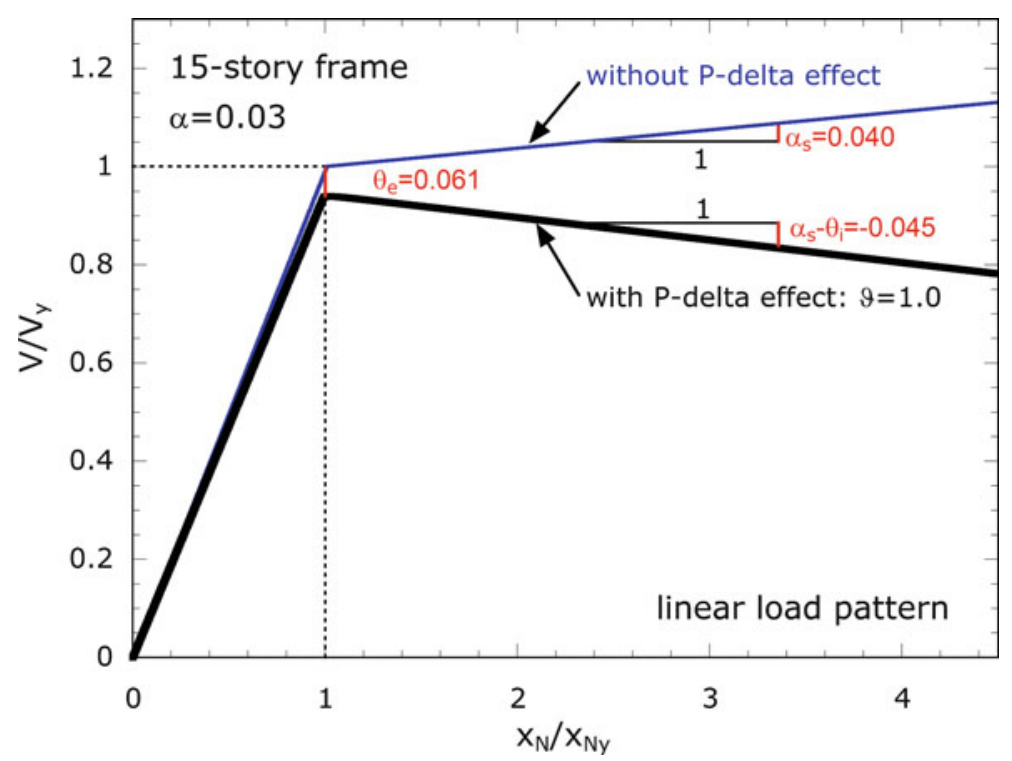

Fig. 4 Global pushover curves of a 15-story frame structure based on a linear load pattern considering and disregarding P-delta effects

ratio between yield base shear $V_{y}$ and total weight $W\left(\gamma=V_{y} / W\right)$, is $\gamma=0.1$. For additional dynamic studies structural damping is considered by means of mass proportional Rayleigh damping of $5 \%$ of the first mode.

Figure 4 shows normalized base shear against normalized roof drift relations of this structure as a result of static pushover analyses utilizing an inverted triangular load pattern both considering and omitting gravity loads, respectively. Axial gravity loads are based on a ratio of life load plus dead load to dead load of 1.0, i.e. coefficient $\vartheta=1.0$. Both global pushover curves exhibit a sharp transition from elastic to inelastic branch of deformation. This behavior can be attributed to specific tuning of the yield strength as specified above. The graphs of this figure demonstrate the expected softening effect of the gravity loads. Both elastic and inelastic global stiffness decrease. For this particular structure the presence of gravity loads leads to a negative stiffness in the post-yield range of deformation. From this outcome it can be concluded that this frame structure may become vulnerable to collapse induced by global P-delta effects.

From the global pushover curve without P-delta a global hardening ratio $\alpha_{S}$ of 0.040 can be identified, which is larger than the individual hardening coefficients $\alpha$ of the rotational springs of 0.03 .

As outlined by Medina and Krawinkler [20] there is no unique global stability coefficient for those structures, which cannot be modeled a priori as SDOF systems. The global force-displacement behavior represented by the global pushover curve exhibits in its bilinear approximation an elastic stability coefficient and an inelastic stability coefficient, compare with Fig. 4. Recall that a stability coefficient is a measure of the decrease of the structural stiffness caused by gravity loads. 


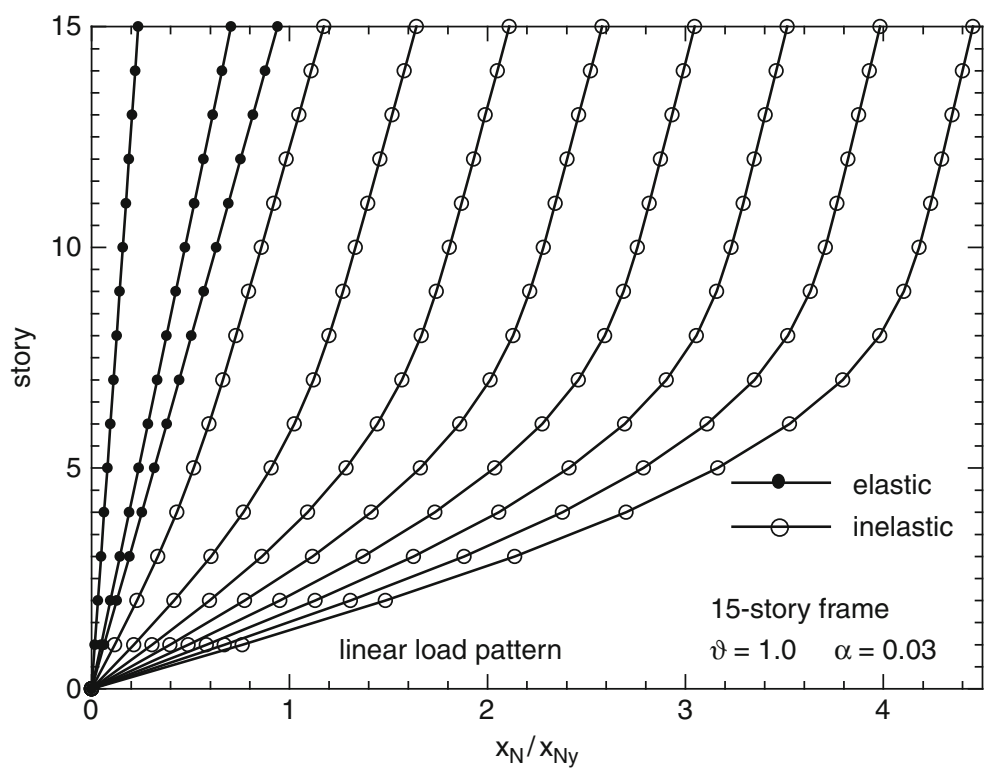

Fig. 5 Deflected shapes of a 15-story frame structure from a pushover analysis

For the actual example problem the following elastic stability coefficient $\theta_{e}$ and inelastic stability coefficient $\theta_{i}$ can be determined: $\theta_{e}=0.061, \theta_{i}=0.085$. The negative slope of the normalized post-yield stiffness is expressed by the difference $\alpha_{S}-\theta_{i}=-0.045$.

In Fig. 5 corresponding displacement profiles of the frame structure in presence of P-delta effects are depicted. As long as the structure is deformed elastically the deflected shapes are relatively close to a straight line. However, once the structure yields there is a concentration of the maximum story drifts in the lower stories. As the roof displacement increases, the bottom story drift values increase at a rapid rate [20]. This concentration of the displacement in the bottom stories is characteristic for regular frame structures vulnerable to the P-delta effect. Comparative calculations have shown that the displacement profiles are close to a straight line even in the inelastic range of deformation when gravity loads are disregarded.

\section{Assessment of the Global Collapse Capacity}

\subsection{Incremental Dynamic Analysis}

Incremental Dynamic Analysis (IDA) is an established tool in earthquake engineering to gain insight into the non-linear behavior of seismic excited structures [21]. Subsequently, the application of IDAs for predicting the global collapse capacity of multi-story frame structures, which are vulnerable to P-delta effects, is summarized. 
For a given structure and a given acceleration time history of an earthquake record dynamic time history analyses are performed repeatedly, where in each subsequent run the intensity of the ground motion is incremented. As an outcome a characteristic intensity measure is plotted against the corresponding maximum characteristic structural response quantity for each analysis. The procedure is stopped, when the response grows to infinity, i.e. structural failure occurs. The corresponding intensity measure of the ground motion is referred to as collapse capacity of the building for this specific ground motion record. There is no unique definition of intensity of an earthquake record. Examples of the intensity measure are the peak ground acceleration (PGA) and the 5\% damped spectral acceleration at the structure's fundamental period $S_{a}\left(T_{1}\right)$.

Since the result of an IDA study strongly depends on the selected record, IDAs are performed for an entire set of $n$ ground motion records, and the outcomes are evaluated statistically. In particular, the median value of the individual collapse capacities $C C_{i}, i=1, \ldots, n$, is considered as the representative collapse capacity $C C$ for this structure and this set of ground motion records,

$$
C C=\operatorname{med}\left\langle C C_{i}, i=1, \ldots, n\right\rangle
$$

\subsection{Example}

In the following the global collapse capacity of the generic 15-story frame structure presented in Sect. 2.2 is determined. The collapse capacity is based on a set of 40 ordinary ground motion records (records without near-fault characteristics), which were recorded in California earthquakes of moment magnitude between 6.5 and 7, and closest distance to the fault rupture between 13 and $40 \mathrm{~km}$ on NEHRP site class D (FEMA 368, 2000). This set of seismic records, denoted as LMSR-N, has strong motion duration characteristics insensitive to magnitude and distance. A statistical evaluation of this bin of records and its characterization is given in [14].

In Fig. 6 IDA curves are shown for each record with light gray lines. For this example the normalized spectral acceleration at the structure's fundamental period,

$$
\frac{S_{a}\left(T_{1}\right)}{g \gamma}
$$

is utilized as relative intensity measure. This parameter is plotted against the normalized lateral roof displacement $x_{N}$,

$$
\frac{x_{N}}{S_{d}\left(T_{1}\right)}
$$

where $S_{d}$ is the $5 \%$ damped spectral displacement at the fundamental period of vibration. 


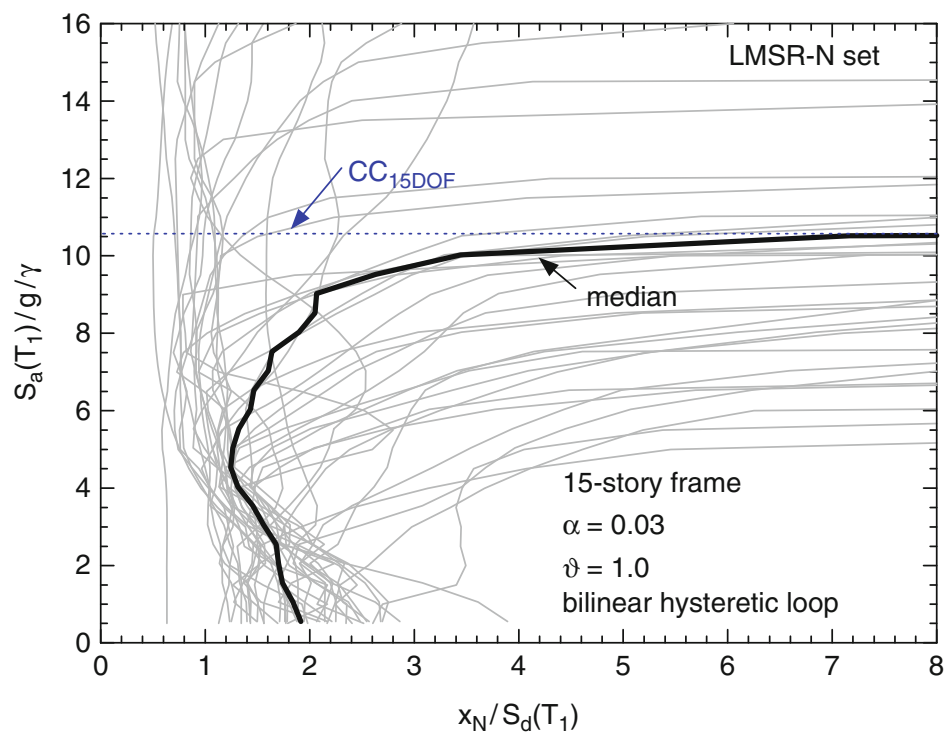

Fig. 6 IDA curves for 40 ground motion records. Median IDA curve. Median collapse capacity $C C_{15 D O F}$ of a generic 15-story frame with a fundamental period of vibration of $3.0 \mathrm{~s}$

Subsequently, an arbitrary IDA curve is picked from the entire set and its behavior discussed exemplary. When the relative seismic intensity is small the structure is deformed elastically. With increasing intensity the normalized roof displacement becomes smaller because energy is dissipated through ductile structural deformations. However, at a certain level of intensity the IDA curves bends at a rapid rate towards collapse. When the IDA curve approaches a horizontal tangent, the collapse capacity of the structure for this particular accelerogram is exhausted. The entire set of IDA curves shows that the IDA study is ground motion record specific. To obtain a meaningful prediction of the global collapse capacity the median IDA curve is determined, which is shown in Fig. 6 by a fat black line. The median IDA curve approaches a horizontal straight dashed line. This line indicates the relative median collapse capacity $C C_{15 D O F}$ of this 15 -degree-of-freedom(15DOF) structure subjected to the LMSR-N bin of records:

$$
C C_{15 D O F}=10.5
$$

Figure 7 shows time histories of normalized interstory drifts of the frame structure in a state of dynamic instability induced by a single seismic event. The corresponding ground motion record "LP89agw" is included in the LMSR-N bin. It can be seen that after time $t=15 \mathrm{~s}$ the ratcheting effect dominates the dynamic response of the bottom stories, i.e. the deformation increases in a single direction. Because the displacements grow to infinity, collapse occurs at a rapid rate. The largest interstory drift develops in the first story. With rising story number the relative story 


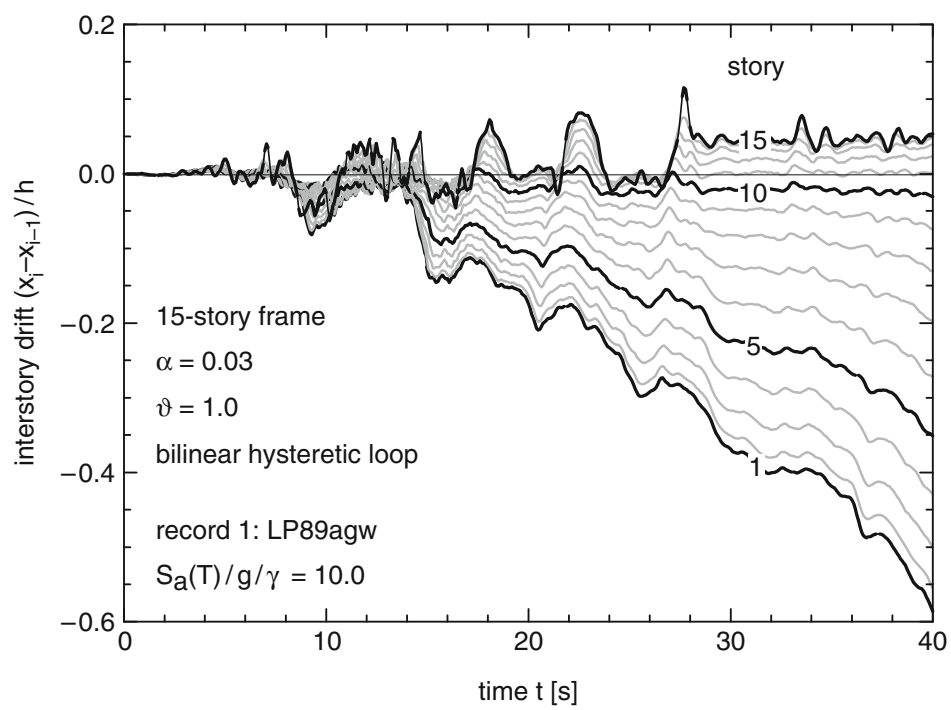

Fig. 7 Global collapse of the 15-story frame structure induced by an individual ground motion record: time history of normalized interstory drifts

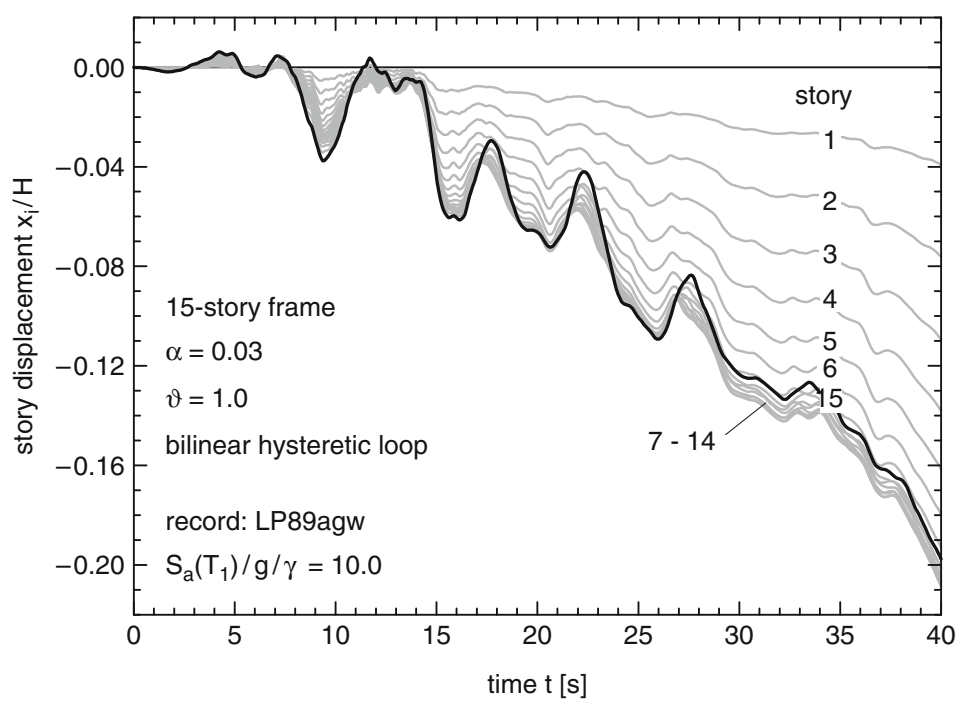

Fig. 8 Global collapse of the 15-story frame structure induced by an individual ground motion record: time history of normalized story displacements

displacements become smaller. In the upper stories a residual deformation remains in opposite direction. This behavior can be attributed to higher mode effects.

The corresponding story displacements are depicted in Fig. 8. They are normalized by the total height $H$ of the structure. With increasing story number the 
interstory drifts accumulate to larger story displacements. However, the largest story displacements do not occur at the roof $(i=15)$ thanks to higher mode effects as illustrated above.

\section{Simplified Assessment of the Global Collapse Capacity}

For large frame structures with many DOFs and a large set of ground motion records the IDA procedure is computational expensive. Thus, it is desirable to provide simplified methods for prediction of the global collapse capacity of structures sensitive to P-delta effects with sufficient accuracy.

Because in regular frame structures P-delta effects are mainly controlled by lateral displacements of the lower stories it is reasonable to assume that these effects can be captured by means of ESDOF systems even in tall buildings in which upper stories are subjected to significant higher mode effects [18]. Application of an ESDOF system requires that shape and structure of the corresponding large frame are regular. Thus, the following considerations are confined to regular planar multi-story frame structures as shown in Fig. 9a, which furthermore exhibit non-deteriorating inelastic material behavior under severe seismic excitation.

a

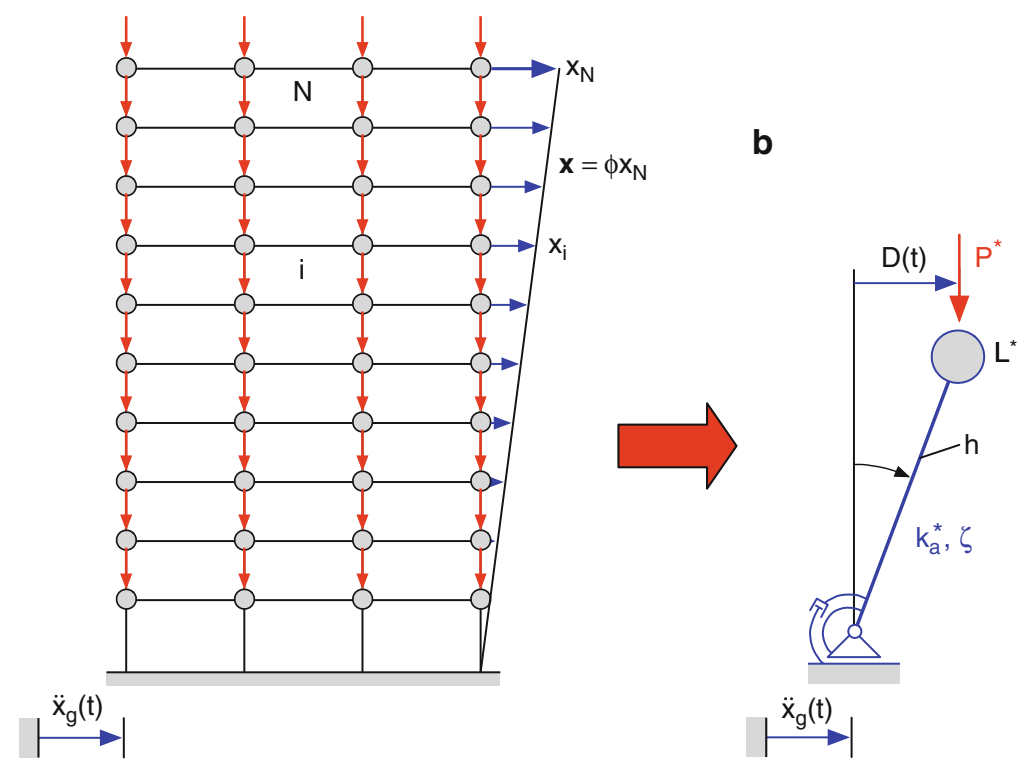

Fig. 9 (a) Multi-story frame structure, and (b) corresponding equivalent single-degree-of-freedom system 


\subsection{Equivalent Single-Degree-of-Freedom System}

The employed ESDOF system is based on a time-independent shape vector $\phi$, which describes the displacement vector $\mathbf{x}$ of the MDOF structure regardless of its magnitude,

$$
\mathbf{x}=\phi x_{N}, \phi_{N}=1
$$

and on global pushover curves of corresponding pushover analyses applied to the original structure disregarding and considering vertical loads, respectively. The lateral pushover load $\mathbf{F}$ is assumed to be affine to the displacement vector $\mathbf{x}$,

$$
\mathbf{F}=\phi F_{N}
$$

Examples of such global pushover curves are shown in Figs. 2 and 4. Details of the proposed ESDOF system can be found in Fajfar [22] and Adam et al. [18].

According to [18] and [22] displacement $D$ of the ESDOF system (Fig. 9b) is related to the roof displacement $x_{N}$ as follows,

$$
D=\frac{m^{*}}{L^{*}} x_{N}, L^{*}=\boldsymbol{\phi}^{\mathrm{T}} \mathbf{M} \mathbf{e}, m^{*}=\boldsymbol{\phi}^{\mathrm{T}} \mathbf{M} \boldsymbol{\phi}
$$

$\mathbf{M}$ is the mass matrix of the original frame structure, and e denotes the influence vector, which represents the displacement of the stories resulting from a static unit base motion in direction of the ground motion $\ddot{x}_{g}$.

The backbone curve of the ESDOF spring force $f_{S}^{*}$ is derived from the base shear $V$ of the global pushover curve (without P-delta effect) according to [18,22]

$$
f_{S}^{*}=\frac{m^{*}}{L^{*}} V
$$

In contrast to a real SDOF system no unique stability coefficient does exist for an ESDOF oscillator, since the backbone curve of the ESDOF system is based on the global pushover curve $[1,20]$. As illustrated in Fig. 10 a bilinear approximation of

Fig. 10 Global pushover curves with and without P-delta effect and their bilinear approximations

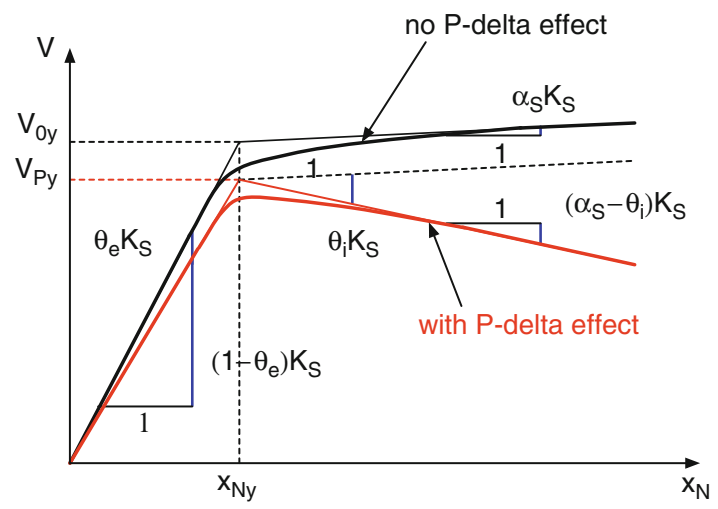


Fig. 11 Backbone curves with and without P-delta effect and auxiliary backbone curve

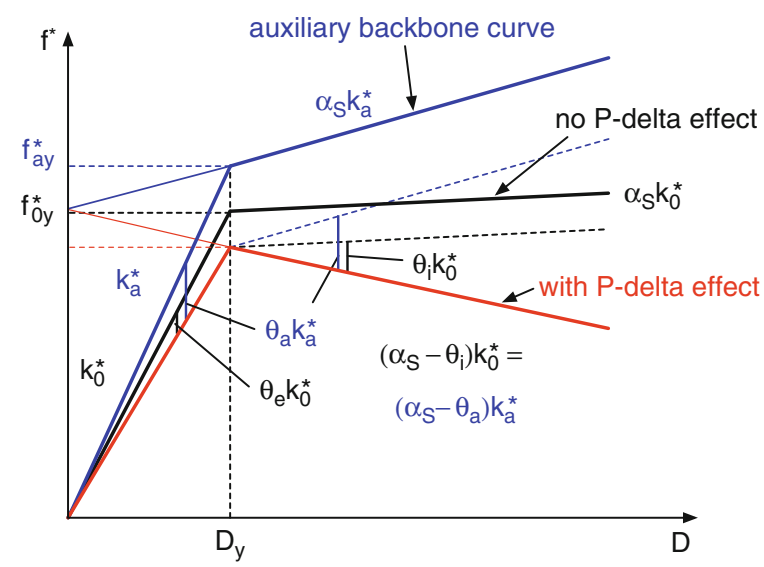

the backbone curve renders an elastic stability coefficient $\theta_{e}$ and an inelastic stability coefficient $\theta_{i}$. Analyses have shown that $\theta_{i}$ is always larger than $\theta_{e}, \theta_{i}>(>) \theta_{e}$ [20]. Thus, loading of the ESDOF system by means of an equivalent gravity load, which is based on the elastic stability coefficient $\theta_{e}$, leads to a "shear deformation" of the hysteretic loop of the ESDOF system, where the post-tangent stiffness is overestimated. Consequently, the hazard of collapse would be underestimated. Ibarra and Krawinkler [4] propose to employ an auxiliary backbone curve, which features a uniform stability coefficient $\theta_{a}$, compare with Fig. 11 . In $[4,18]$ the parameters of the auxiliary backbone curve are derived as:

$$
\theta_{a}=\frac{\theta_{i}-\theta_{e} \alpha_{S}}{v}, k_{a}^{*}=\frac{v}{1-\alpha_{S}} k_{0}^{*}, f_{a y}^{*}=\frac{v}{1-\alpha_{S}} f_{0 y}^{*}, v=1-\theta_{e}+\theta_{i}-\alpha_{S}
$$

Subsequently, an appropriate hysteretic loop is assigned to the auxiliary backbone curve, which is sheared by $\theta_{a}$ when the ESDOF system is loaded by the equivalent gravity force $P^{*}[14]$ :

$$
P^{*}=\theta_{a} k_{a}^{*} h
$$

This situation is illustrated in Fig. 12, where exemplarily a bilinear hysteretic curve is assigned to the auxiliary backbone curve. Now, the normalized equation of motion of the auxiliary ESDOF system can be expressed in full analogy to a real SDOF system as [14]

$$
\frac{1}{\omega_{a}^{* 2}} \ddot{\mu}^{*}+2 \zeta \frac{1}{\omega_{a}^{*}} \dot{\mu}^{*}+\left(\bar{f}_{S}^{*}-\theta_{a} \mu^{*}\right)=-\frac{\ddot{x}_{g}}{g \gamma^{*}}
$$

with

$$
\mu^{*}=\frac{D}{D_{y}}, \bar{f}_{S}^{*}=\frac{f_{a S}^{*}}{f_{a y}^{*}}, \omega_{a}^{*}=\sqrt{\frac{k_{a}^{*}}{L^{*}}}
$$

In Eqs. 11 and $12 \mu^{*}$ is the non-dimensional horizontal displacement of mass $L^{*}$ of the ESDOF, and $D_{y}$ characterizes the yield displacement. $\bar{f}_{S}^{*}$ denotes the 

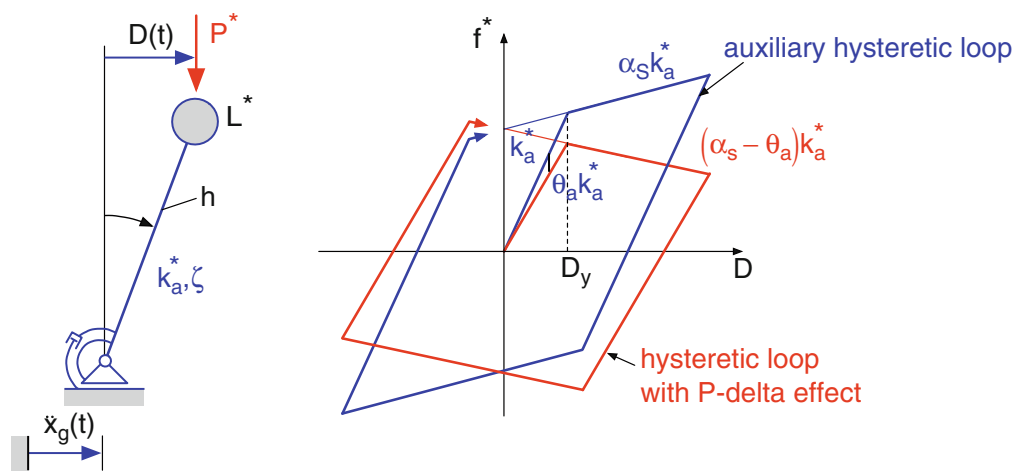

Fig. 12 Auxiliary equivalent single-degree-of-freedom system with bilinear hysteretic behavior

non-dimensional spring force, which is the ratio of the auxiliary spring force $f_{a S}^{*}$ and its yield strength $f_{a y}^{*} \cdot \omega_{a}^{*}$ represents the circular natural frequency of the auxiliary ESDOF system, and $k_{a}^{*}$ is the corresponding stiffness. The equivalent base shear coefficient $\gamma^{*}$ of the ESDOF system is calculated from the base shear coefficient $\bar{\gamma}$ of the MDOF system according to [18]

$$
\gamma^{*}=\frac{\bar{\gamma}}{\lambda_{M D O F}}, \bar{\gamma}=\frac{V_{y}}{M g}, \lambda_{M D O F}=\frac{L^{* 2}}{m^{*} M}
$$

$V_{y}$ is the base shear at the yield point, and $M$ the (dynamic effective) total mass of the MDOF structure.

\subsection{Collapse Capacity Spectra}

Adam et al. [13-15] propose to utilize collapse capacity spectra for the assessment of the collapse capacity of SDOF systems, which are vulnerable to the P-delta effect. In [15] it is shown that the effect of gravity loads on SDOF systems with bilinear hysteretic behavior is mainly characterized by means of the following structural parameters:

- The elastic structural period of vibration $T$

- The slope of the post-tangential stiffness expressed by the difference $\theta-\alpha$ of the stability coefficient $\theta$ and the strength hardening coefficient $\alpha$

- The viscous damping coefficient $\zeta$ (usually taken as 5\%)

In [15] design collapse capacity spectra are presented as a function of these parameters. As an example in Figs. 13 and 14 collapse capacity spectra and the corresponding design collapse capacity spectra, respectively, are shown for SDOF systems with stable bilinear hysteretic behavior [15]. They are based on the LMSR$\mathrm{N}$ set of 40 ground motions. Here, the collapse capacity $C C$ is defined as the median of the 40 individual collapse capacities $C C_{i}, i=1, \ldots, 40$, 


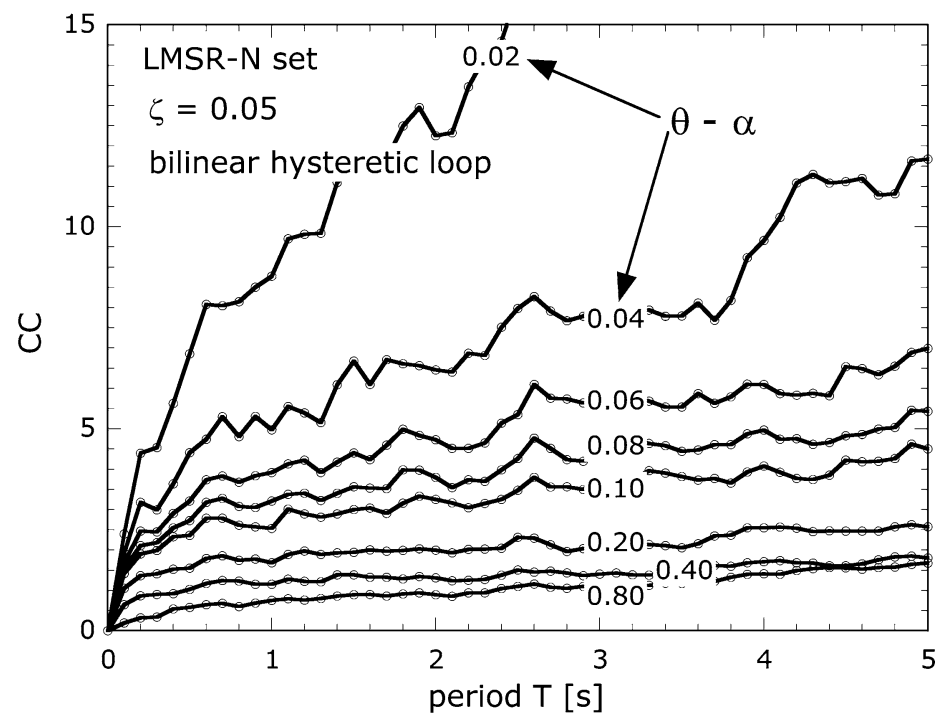

Fig. 13 Collapse capacity spectra of single-degree-of-freedom systems with bilinear hysteretic loop

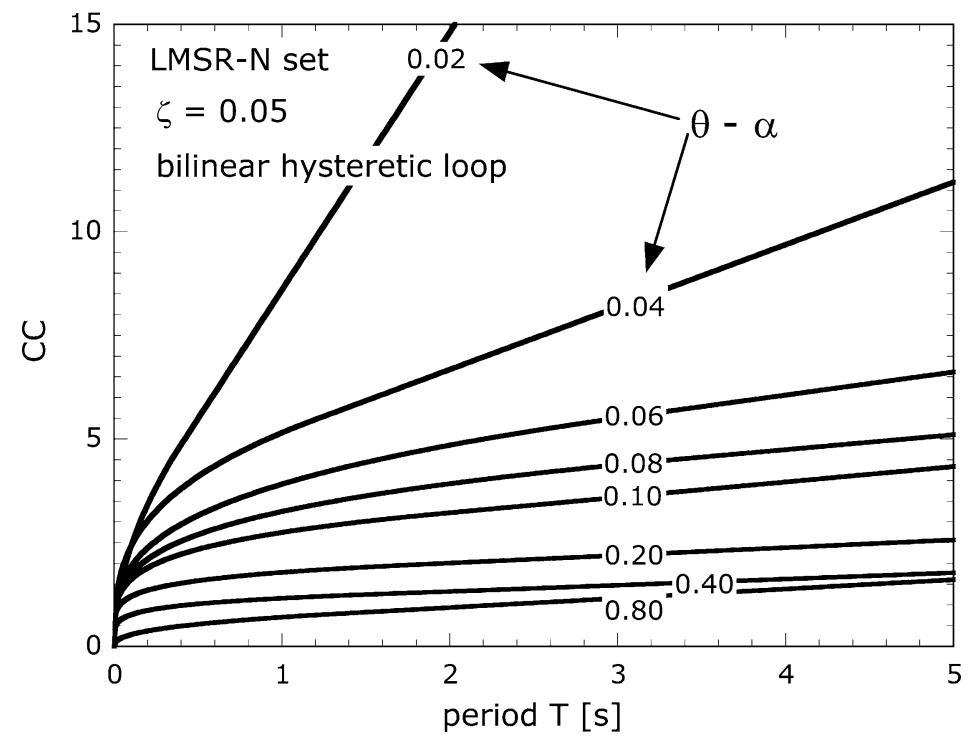

Fig. 14 Design collapse capacity spectra of single-degree-of-freedom systems with bilinear hysteretic loop 


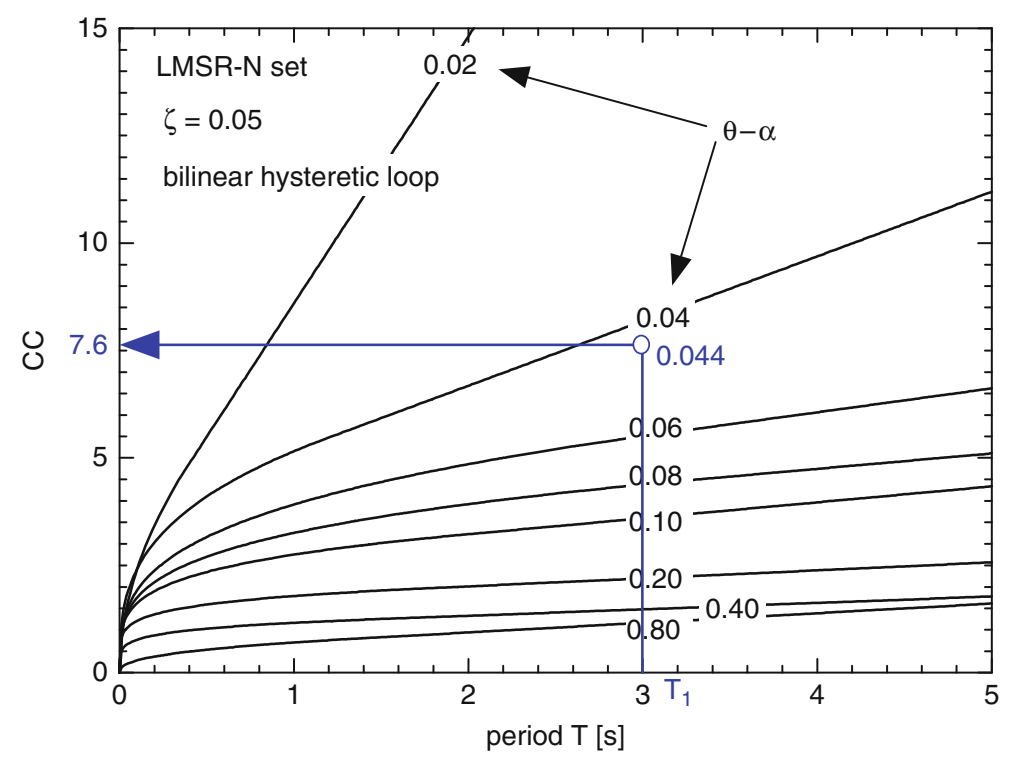

Fig. 15 Application of design collapse capacity spectra to an equivalent single-degree-of-freedom system

$$
C C=\operatorname{med}\left\langle C C_{i}, i=1, \ldots, 40\right\rangle
$$

which are for these spectra the 5\% damped spectral acceleration at the period of vibration $T$, where structural collapse occurs [15],

$$
C C_{i}=\frac{\left.S_{a}(T)\right|_{i}}{g \gamma}
$$

Application of design collapse capacity spectra is simple: an estimate of the elastic period of vibration $T$, stability coefficient $\theta$ and hardening ratio $\alpha$ of the actual SDOF structure need to be determined. Subsequently, from the chart the corresponding collapse capacity $C C$ can be read as shown in Fig. 15.

\subsection{Application of Design Collapse Capacity Spectra to Multi-Story Frame Structures}

ESDOF systems allow the application of design collapse capacity spectra for assessing the collapse capacity of multi-story frame structures. Thereby, $T$ and $\theta-\alpha$ of a SDOF system are replaced by the fundamental period $T_{1}$ of the actual MDOF system (without P-delta), and the difference of the auxiliary stability coefficient and hardening coefficient $\theta_{a}-\alpha_{S} . \alpha_{S}$ is the hardening coefficient taken from the global pushover curve without P-delta effect. From the design collapse capacity spectrum 
a prediction of the related collapse capacity $C C$ is obtained. The actual collapse capacity of the ESDOF system, i.e. the normalized median intensity of earthquake excitation at collapse, is subsequently determined from, compare with Eq. 13,

$$
C C_{E S D O F}=\frac{C C}{\lambda_{M D O F}}
$$

This outcome represents an approximation of the collapse capacity $C C_{M D O F}$ of the actual MDOF building,

$$
C C_{M D O F} \approx C C_{E S D O F}
$$

\subsection{Example}

In an example problem the application of ESDOF systems and collapse spectra for the prediction of the global collapse capacity of multi-story frame structures is illustrated. For this purpose the generic 15-story frame structure of Sect. 2.2 is utilized. Recall that the fundamental period of this structure is $T_{1}=3.0 \mathrm{~s}$, and the elastic stability coefficient, the inelastic stability coefficient and the hardening ratio, respectively, are: $\theta_{e}=0.061, \theta_{i}=0.085, \alpha_{S}=0.040$. The auxiliary stability coefficient according to Eq. 9 is $\theta_{a}=0.084$, and thus $\theta_{a}-\alpha_{S}=0.044$. Coefficient $\lambda_{M D O F}$, Eq. 13 , is derived as: $\lambda_{M D O F}=0.774$.

Application of design collapse capacity spectra as illustrated in Fig. 15 renders the collapse capacity $C C=7.6$. Division by the coefficient $\lambda_{M D O F}$ results in the collapse capacity of the ESDOF system,

$$
C C_{E S D O F}=7.6 \frac{1}{0.774}=9.83
$$

Comparing this outcome with the result of the IDA procedure on the actual 15-story frame structure according to Eq. $4, C C_{15 D O F}=10.5$, reveals that $C C_{E S D O F}$ is for this example a reasonable approximation of the collapse capacity.

In addition, Fig. 16 shows the collapse capacity of the 15-story frame for different magnitudes of gravity loads, i.e. the ratio $\vartheta$ of life plus dead load to dead load is varied from 1.0 to 1.6. The latter value is considered only for curiosity. Median, $16 \%$ percentile and $84 \%$ percentile collapse capacity derived from IDAs are depicted by black lines. These outcomes are set in contrast to the median collapse capacity from a simplified assessment based on ESDOF systems and collapse capacity spectra represented by a dashed line. It can be seen that in the entire range the simplified prediction of the collapse capacity underestimates the "exact" collapse capacity. In other words, the simplified methodology renders for this example results on the conservative side. Note that the modification of the fundamental period $T_{1}$ by Pdelta is not taken into account. 


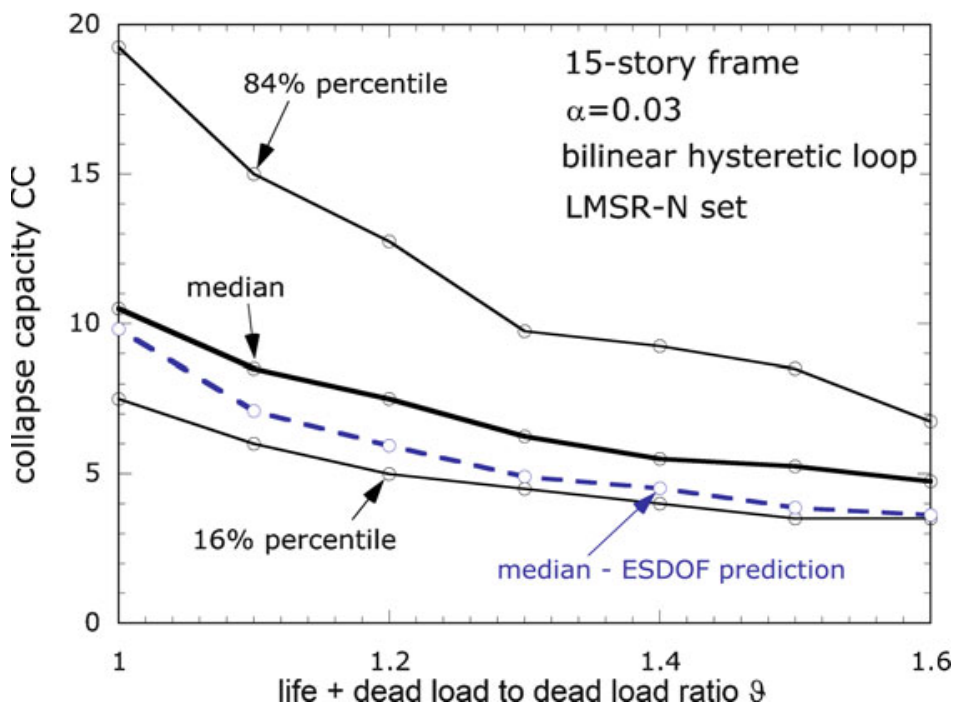

Fig. 16 Collapse capacity of a 15 -story frame structure for different magnitudes of gravity loads. Comparison with simplified assessment (dashed line)

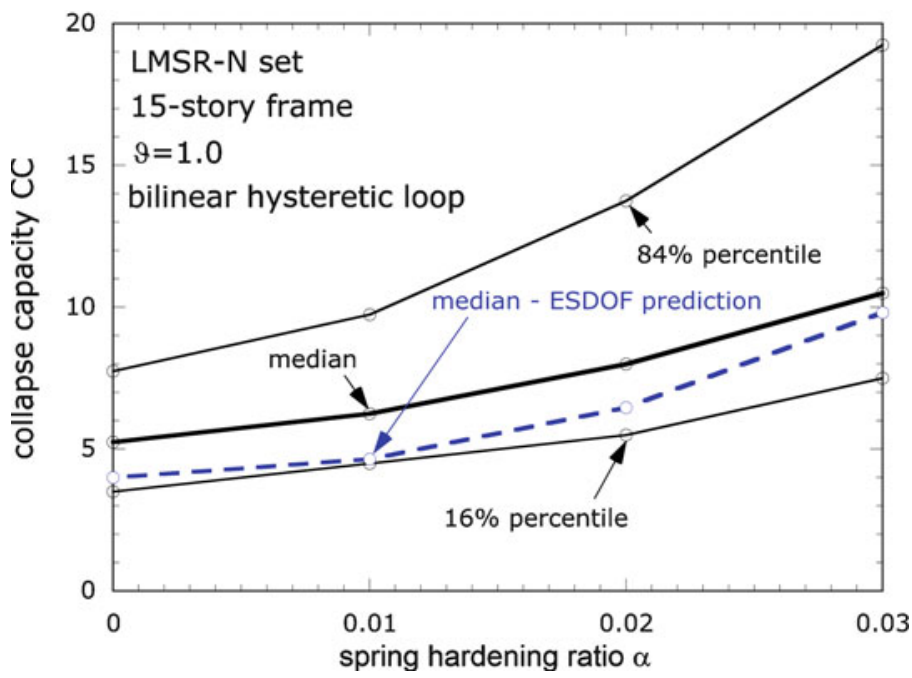

Fig. 17 Collapse capacity of a 15-story frame structure for different hardening ratios of the bilinear springs. Comparison with simplified assessment (dashed line)

The same holds true when the hardening ratio of the bilinear springs is varied from 0.0 to 0.03 , compare with Fig. 17. Application of ESDOF systems combined with collapse spectra renders median collapse capacities smaller than the actual ones. As expected it can be observed that the collapse capacity rises with increasing post-yield stiffness. 


\section{Conclusions}

The vulnerability of seismic excited flexible inelastic multi-story frame structures to dynamic instabilities has been evaluated. In particular a simplified methodology for assessment of the global collapse capacity has been proposed, which is based on equivalent single-degree-of-freedom systems and collapse capacity spectra. The result of an example problem presented in this study suggests that the application of equivalent single-degree-of-freedom systems and collapse capacity spectra is appropriate to estimate the seismic P-delta effect in highly inelastic regular multi-story frame structures provided that they exhibit non-deteriorating inelastic material behavior under severe seismic excitation.

\section{References}

1. Bernal D (1998) Instability of buildings during seismic response. Eng Struct 20:496-502

2. Gupta A, Krawinkler H (2000) Dynamic P-delta effect for flexible inelastic steel structures. J Struct Eng 126:145-154

3. Aydinoglu MN (2001) Inelastic seismic response analysis based on story pushover curves including P-delta effects. Report No. 2001/1, KOERI, Istanbul, Department of Earthquake Engineering, Bogazici University

4. Ibarra LF, Krawinkler H (2005) Global collapse of frame structures under seismic excitations. Report No. PEER 2005/06, Pacific Earthquake Engineering Research Center, University of California, Berkeley, CA

5. Lignos DG, Krawinkler H (2009) Sidesway collapse of deteriorating structural systems under seismic excitations. Report No. TB 172, John A. Blume Earthquake Engineering Research Center, Department of Civil and Environmental Engineering, Stanford University, Stanford, CA

6. Asimakopoulos AV, Karabalis DL, Beskos DE (2007) Inclusion of the P- $\Delta$ effect in displacement-based seismic design of steel moment resisting frames. Earthquake Eng Struct Dyn 36:2171-2188

7. Villaverde R (2007) Methods to assess the seismic collapse capacity of building structures: state of the art. J Struct Eng 133:57-66

8. Bernal D (1987) Amplification factors for inelastic dynamic P- $\Delta$ effects in earthquake analysis. Earthquake Eng Struct Dyn 15:635-651

9. MacRae GA (1994) P- $\Delta$ effects on single-degree-of-freedom structures in earthquakes. Earthquake Spectra 10:539-568

10. Kanvinde AM (2003) Methods to evaluate the dynamic stability of structures - shake table tests and nonlinear dynamic analyses. In: EERI Paper Competition 2003 Winner. Proceedings of the EERI Meeting, Portland

11. Vian D, Bruneau M (2003) Tests to structural collapse of single degree of freedom frames subjected to earthquake excitation. J Struct Eng 129:1676-1685

12. Miranda E, Akkar SD (2003) Dynamic instability of simple structural systems. J Struct Eng 129:1722-1726

13. Adam C, Spiess J-P (2007) Simplified evaluation of the global capacity of stability sensitive frame structures subjected to earthquake excitation (in German). In: Proceedings of the D-A-CH meeting 2007 of the Austrian association of earthquake engineering and structural dynamics, September 27-28, 2007, Vienna, CD-ROM paper, paper no. $30,10 \mathrm{pp}$ 
14. Adam C (2008) Global collapse capacity of earthquake excited multi-degree-of-freedom frame structures vulnerable to P-delta effects. In: Yang YB (ed) Proceedings of the Taiwan - Austria joint workshop on computational mechanics of materials and structures, 15-17 November 2008, National Taiwan University, Taipei, Taiwan, pp 10-13

15. Adam C, Jäger C (submitted) Seismic collapse capacity of basic inelastic structures vulnerable to the P-delta effect

16. Takizawa H, Jennings PC (1980) Collapse of a model for ductile reinforced concrete frames under extreme earthquake motions. Earthquake Eng Struct Dyn 8:117-144

17. Bernal D (1992) Instability of buildings subjected to earthquakes. J Struct Eng 118:2239-2260

18. Adam C, Ibarra LF, Krawinkler H (2004) Evaluation of P-delta effects in non-deteriorating MDOF structures from equivalent SDOF systems. In: Proceedings of the 13th World Conference on Earthquake Engineering, 1-6 August 2004, Vancouver BC, Canada. DVD-ROM paper, $15 \mathrm{pp}$, Canadian Association for Earthquake Engineering

19. Adam C, Jäger C (2010) Assessment of the dynamic stability of tall buildings subjected to severe earthquake excitation. In: Proceedings of the International Conference for highrise towers and tall buildings 2010, 14-16 April 2010, Technische Universität München, Munich, Germany. CD-ROM paper, 8 pp

20. Medina RA, Krawinkler H (2003) Seismic demands for nondeteriorating frame structures and their dependence on ground motions. In: Report No. 144, John A. Blume Earthquake Engineering Research Center, Department of Civil and Environmental Engineering, Stanford University, Stanford, CA

21. Vamvatsikos D, Cornell CA (2002) Incremental dynamic analysis. Earthquake Eng Struct Dyn 31:491-514

22. Fajfar P (2002) Structural analysis in earthquake engineering - a breakthrough of simplified non-linear methods. In: Proceedings of the 12th European Conference on Earthquake Engineering, CD-ROM paper, Paper Ref. 843, 20 pp, Elsevier 